\title{
Metacognitive Self and Motivation to Seek Diagnostic Information About the Self: A Longitudinal Study
}

\author{
Hanna Brycz ${ }^{1 *}$, Paweł Kleka ${ }^{2}$, Agnieszka Fanslau ${ }^{1}$ and Aleksandra Pilarska ${ }^{2}$ \\ ${ }^{1}$ Institute of Psychology, University of Gdansk, Gdansk, Poland, ${ }^{2}$ Faculty of Psychology and Cognitive Science, \\ Adam Mickiewicz University, Poznan, Poland
}

OPEN ACCESS

Edited by:

Sviatlana Kamarova,

Curtin University, Australia

Reviewed by:

Sharinaz Hassan,

Curtin University, Australia Katarzyna Stasiuk,

Jagiellonian University, Poland

*Correspondence: Hanna Brycz

hanna.brycz@ug.edu.pl

Specialty section:

This article was submitted to

Educational Psychology,

a section of the journal

Frontiers in Education

Received: 23 June 2019 Accepted: 04 October 2019 Published: 18 October 2019

Citation:

Brycz H, Kleka P, Fanslau A and Pilarska A (2019) Metacognitive Self and Motivation to Seek Diagnostic Information About the Self: A

Longitudinal Study.

Front. Educ. 4:117.

doi: 10.3389/feduc.2019.00117
This longitudinal study was designed to test the hypothesis that the strength of metacognitive self would predict the level of motivation to obtain self-diagnostic information. We begin by defining the construct of metacognitive self as a cognitive-motivational concept that pertains to the individuals' self-awareness of biases. We then discuss the role of acquiring diagnostic information about the self in enhancing self-regulation. We predicted that stronger metacognitive self would be associated with greater motivation for seeking diagnostic information about the self, including both positive and negative feedback. More than 400 undergraduate university students participated in the 2.5-years longitudinal study. Participants were tested 5 times, with 6-months intervals, using measures of metacognitive self (Metacognitive Self Questionnaire; MCSQ-21) and the need for diagnostic information about the self (Self-Diagnostic Motive Scale; SDMS). As expected, participants with high metacognitive self sought diagnostic information about themselves significantly more than those low in metacognitive self. This effect was observed at each of the five measurement points. We conclude that individuals characterized by greater insight into their own biases are more highly motivated to obtain feedback about themselves that can be used for accurate assessment of their strengths and weaknesses and for self-improvement.

Keywords: metacognition, diagnostic information, biases, motivation, longitudinal study

\section{INTRODUCTION}

\section{Metacognitive Self and Its Motivational Function}

Metacognition is broadly defined as awareness and understanding of own cognitive processes. In our research, we focused on a specific aspect of metacognition, namely metacognitive self (MCS), which is defined as the insight into own biased thinking. We will briefly introduce the construct, placing it within the context of the metacognition research.

The interest in metacognition goes back at least to the times of Aristotle (Sachs, 2001). However, the term "metacognition," understood as cognition of own cognition, was introduced by developmental and cognitive psychologists in the last century (Flavell, 1979). More recently, metacognition research expanded in scope to fields, such as working memory and consciousness (Schraw and Dennison, 1994; Koriat, 2007), creativity (Scholer and Miele, 2016), judgment, decision-making, and persuasion (See et al., 2008), children's cognitive development (Flavell, 1979), problem solving and memory (Nelson and Narens, 1990), critical thinking processes, attitude change, and bias regulation (Brinol and DeMarree, 2012). The important finding emerging from this large body of research is that metacognition plays a crucial role in the process of human 
self-regulation (Baumeister and Vohs, 2004). Schwarz (2015) claimed that acquiring metacognitive pieces of knowledge can fluctuate due to the mental resources' accessibility and the level of difficulty of knowledge to be learned. The level of fluency creates metacognitive experience of the dynamics of one's own information processing. Such experience of ease or difficulty was defined as conceptual fluency (Whittlesea, 1993). Thus, the interpretation of metacognitive experience depends on the complexity and richness of one's cognitive network and accessible lay theories (i.e., naive psychological theories commonly held by people; Nisbett and Ross, 1980). Moreover, metacognitive experience is context sensitive. Fluent processing increases positive feelings and the likelihood of information acceptance. Once false information or misinformation, such as linking vaccination and autism, has been accepted, it is very difficult to correct (Schwarz, 2015). The ability to question one's own beliefs seems to be rooted in individuals' epistemic needs (Kruglanski, 1989) and intrinsic motivation for self-knowledge (Higgins and Kruglanski, 2000).

It can be assumed that people differ in their level of intrinsic motivation and epistemic need to ask themselves about reasons why their way of thinking or behavior might be wrong (e.g., Kross and Ayduk, 2017). Some individuals can be expected to be more strongly motivated to recognize their biases than others. Based on these findings, we reasoned that the metacognitive experience, connected with metacognitive feelings, and the level of intrinsic epistemic motivation shape the individual's awareness of biases.

As we conceptualized metacognitive self as self-awareness of biases, it is important to review current understanding of biases. Biases are deviations from the common rationality, also referred to as the psychological regularities (Larrik, 2004). For example, people tend to overestimate their future success (Koriat et al., 1980; Weiner, 2014) and underestimate the time needed to accomplish a task and achieve a goal (Buchler et al., 1994). This discrepancy arises because people tend to ignore potential distractors and are focused on what might expedite success (teleological approach). Biases and shortcuts might also be anchored in heuristics (Weiner, 1972; Kahneman and Tversky, 1973). Insight into one's own biases is what we refer to as metacognitive self. Individuals with high level of MCS successfully identify biases in their own actions, reasoning, and judgment, while those low in MCS fail to acknowledge that they fall victim to common biases.

As pointed out earlier, accurate insight into the biases one holds (i.e., strong MCS) requires motivation and cognitive capacity to search for reasons why one might be wrong. Note that such self-questioning attitude implicitly assumes that an individual possesses the perceptual ability to recognize own inaccurate behavior or cognition. It may be then argued that lack of a need to question one's own biases implies low metacognitive self and low need for accurate self-knowledge. Conversely, strong desire to gain insight into one's own biases may be seen as a necessary (although not sufficient) condition for high metacognitive self. The metacognitive experience that accompanies active and self-initiated reflection about one's self may then lead to greater self-understanding and knowledge of the self in general.
Emphasizing the cognitive-motivational basis of MCS, we posit that the strength of MCS is associated with stronger motivation to search for self-diagnostic information.

\section{Motivation to Search for Self-Diagnostic Information}

Self-diagnostic information is a particular type of self-knowledge. Tversky (1977) postulated the diagnosticity principle, which identifies features that are used to cluster objects into subgroups in human mind (context dependent effect). This principle assumes that while perceived similarity between objects enclosed in one cluster increases, the analogs similarity between objects composing a different cluster decreases. The diagnosticity principle is also referred to as the law of the human mind structuring. Usually, researchers create the indexes of diagnosticity (e.g., posterior probability, information gain, based on Bayesian algorithms). Regardless of the method of measuring diagnosticity, social psychology refers the concept to the capability of the retrieved cues to form a solution for the judgment task at hand (Simmons et al., 1993). The objective of diagnosticity is to acquire and comprehend information about social objects, especially the self, as the clusters are formed about the social objects: self and others.

Properties or features of the self may be less or more diagnostic. Ling et al. (2012) discuss how people reach conclusions when self-diagnosing their health conditions. The authors claim that "self-diagnosis is contingent upon an individual's ability to combine memory-based information about past behavior and experiences with symptoms with information available in the context (...) to assess whether or not he or she is at risk and (...) to seek treatment" (p. 2112). It is also highlighted that self-diagnosis serves pro-health behaviors and self-regulatory functions. The self-diagnosis (concerning not only health, but also social relations or self-description) is based on motivation to search for self-diagnostic (i.e., salient, meaningful, systematically reflected) information. Bassok and Trope (1984) showed that people quite often use diagnostic strategies to clearly distinguish between the hypothesis and its alternative (here, the hypothesis about self).

Other researchers showed overwhelming drive in human beings to search for positive information about the self (i.e., selfenhancement motive). Sedikides and Strube (1997) distinguished four motives of human knowledge acquisition about the self: self-enhancement, self-verification, self-assessment, and selfimprovement. The authors' model, which integrates different research theories in self-motives tradition, is referred to as the Self-Concept Enhancing Tactician Model (SCENT). In accordance with the SCENT model, the self-motives can be sometimes activated simultaneously and interact with each other. For example, the self-assessment motive and the selfimprovement motive function as an interactive set of motives connected with the process of gaining knowledge about oneself. The first one aims at obtaining information about what is the present characteristics of an individual, while the second focuses on searching for indications of how such characteristics can be improved in the future (Sedikides and Skowronski, 
2000, 2009). At the same time, individuals may possess the desire for continuous self-improvement in order to truly get to know themselves and their limits. Although self-assessment and self-improvement are likely to be related, the two can be distinguished conceptually. As pointed out by Taylor et al. (1995), if individuals have models on which they can base their behavior, they may not be motivated to increase self-knowledge to improve themselves.

Trope and Neter (1994), among others, focused on the role of positive experience in searching for diagnostic information. In their study, the participants were given either positive or negative feedback on a task, or were led to experience either positive or negative mood, and were then asked to choose the type of feedback they preferred in a different feedback situation. The results showed that individuals who received feedback about their failures in the initial task or were in a negative mood preferred self-enhancing information in the subsequent task, while participants who were informed about their successes or were in a positive mood subsequently preferred feedback that focused on their liabilities. Such feedback was unpleasant but informative and could serve as a basis for self-improvement. The findings suggest that the relative importance of esteemand accuracy-related needs may depend on one's resources to cope with the immediate emotional costs of negative feedback. However, as pointed out by Trope and Neter (1994), "when the informational value of the feedback is high, individuals may make intentional efforts to control their decision. They may see acquisition of the feedback as rational and may actively resist temptations to avoid it" (p. 647). Of importance, previous studies have demonstrated that high MCS can serve as a buffer against ego depletion (Brycz et al., 2014).

Furthermore, using a diagnostic strategy in information search involves asking highly diagnostic questions, for example, why one was wrong, and preferring highly diagnostic tasks. Moreover, a diagnostic orientation is characterized by the same interest in both favorable and unfavorable information that concerns the self (Landau et al., 2010). Yet, as most research results demonstrate, individuals show strong preference for information, which is at the same time diagnostic and positive (Morrison and Cummings, 1992).

It has been shown via experimental studies that individuals with strong MCS seek any type of feedback more often than those with weak MCS. Furthermore, compared to those low in MCS, those high in MCS participants are more interested in acquiring self-knowledge through negative feedback (e.g., Brycz et al., 2018). This suggests that individuals high in MCS are more apt to engage in self-diagnosis than those with low MCS. Consistent with findings that people with high MCS seek diagnostic information more than those with low MCS, we expected the self-evaluation of those with high MCS to be more influenced by self-diagnostic motives, especially by self-assessment and selfimprovement, than by self-enhancement need.

In summary, our predictions were as follows:

- We expected a weak to moderate effect of metacognitive self (MCS) as a predictor for motivation to seek selfdiagnostic information (SDMS) as measured 6 months later
(Hypothesis 1). This approach allowed us to assess the prospective impact of MCS on SDMS.

- We further expected a moderate to strong relation between MCS and SDMS, each measured at the same measurement point (Hypothesis 2).

- Of the three types of feedback people may seek, namely own results information (ORI), self-improvement information (SII), and comparison information (CI), we expected moderate to strong concurrent relations of MCS with SII and ORI subscales. This would indicate that the pure self-improvement motive (SII) and self-assessment based on the evaluation of one's performance (ORI) are both related to MCS. As CI combines self-enhancement and self-improvement motives, we expected its relation to MCS to be less evident (Hypothesis 3).

\section{MATERIALS AND METHODS}

To examine whether metacognitive self (MCS) predicts seeking self-diagnostic information (SDMS), a multi-year longitudinal study has been designed. Both MCS and SDMS were assessed at five time-points. This allowed us to test MCS as a concurrent and 6-months prospective predictor of SDMS.

\section{Participants}

Participants in the study were all recruited randomly among undergraduate university students at University of Gdansk. We chose to focus on the student population because they face many challenging tasks and life-direction determining decisions (e.g., the task of exploring and forming a coherent sense of identity) as well as because they are likely to receive frequent feedback concerning themselves in both academic and social spheres (e.g., Taylor et al., 1995; Arnett, 2000). Hence, this population of emerging adults can be seen to be in particular need of selfevaluation, possibly greater than younger or older individuals.

Five assessments were performed every 6 months during a period of 2.5 years. Some students from the initial recruitment were further excluded because of their extended absence from the University due to participation in an Erasmus exchange programme, leave of absence, or failure to meet academic requirements. Due to this dropout, additional students were recruited at further stages of the study. A total of $N=406$ students (369 females and 37 males) participated in the first wave of the study (during the summer semester of the first year of university study; March-April 2014). The second wave (winter semester; November-December 2014) involved $N=$ 382 students ( 346 females and 36 males). The third assessment (summer semester; March-April 2015) was completed by $N=$ 341 students (310 females and 31 males) and the sample of the fourth assessment (winter semester; November-December 2015 ) included $N=339$ students (306 females and 33 males). In the fifth and final wave (summer semester; March-April 2016) $N=352$ students ( 321 females and 31 males) were tested. In summary, of the 406 participants who completed the initial assessment, 329 completed all five assessments. Each sample was dominated by females, which is representative of the student population at the Departments of Humanities and Social Sciences 
of the University of Gdansk, where most of the recruitment took place.

The average age of the students at the first assessment was 20.10 years $(S D=2.66, M d n=20)$. Along all five waves of the study, the age range of the participants was from 19 to 23 .

\section{Measures}

Two questionnaires were used in this study. The first, the Metacognitive Self Questionnaire (MCSQ-21; see Brycz et al., 2019, for validity and reliability data), is a 21-item selfreport measure of metacognitive self. Each item is a colloquial behavioral description of a given bias, for example "I tend to judge other people positively rather than negatively" (positivity bias). Participants assessed to what extent they believe each described behavior applies to them, using a 6 point Likert scale from 1 (definitely disagree) to 6 (definitely agree).

The second questionnaire used was the Self-Diagnostic Motive Scale (SDMS; see Brycz et al., 2018, for details on validity and reliability of the scale). SDMS measures the desire to obtain diagnostic information about the self. It contains 6 items, divided among three subscales: own results information (ORI) measures the extent in which one is interested in feedback on whether the task was performed correctly and whether the task was executed incorrectly; self-improvement information (SII) measures the extent in which one would like to know about ways to improve their performance and about behavioral changes that would help with that; comparison information (CI) measures the extent in which one would like to receive feedback about the extent to which they performed better on the task relative to the others and about the extent to which they performed worse than the others. The threefactor structure of the scale was examined through exploratory factor analysis and later confirmed through confirmatory factor analysis. Conceptually, the first two motives, ORI and SII, focus entirely on the self and reflect, respectively, self-assessment and self-improvement. However, the third motive, namely CI, is more complex, since it includes feedback on both oneself and others and both "downward" and "upward" comparisons. Downward comparison (to those who did worse) fulfill self-enhancement needs, while upward comparisons (to those who did better) may facilitate setting self-improvement goals (Monteil and Michinov, 1996). The SDMS items were presented as questions, for example, "How much would you like to know ... to what extent did I complete the task worse than others" (CI). All items were evaluated on a six-point Likert scale from 1 (definitely not) to 6 (definitely yes).

The reliability of the MCSQ-21 and the SDMS was assessed on the basis of Cronbach's alpha, McDonald's omega, and Guttman's lambda. As can be seen from Table 1, the internal consistencies of the MCSQ-21 and the SDMS were satisfactory for each sample at each of the five measurements.

\section{Procedure}

The research was approved by the Polish Ethical Committee at the University of Gdansk, Poland (decision 17a/2013). All students enrolled in the study were given written information on the use and confidentiality of their personal data and signed
TABLE 1 | Reliability estimates of the MCSQ-21 and the SDMS.

\begin{tabular}{lccccc}
\hline MCSQ-21 & Wave 1 & Wave 2 & Wave 3 & Wave 4 & Wave 5 \\
\hline alpha & 0.681 & 0.733 & 0.791 & 0.760 & 0.797 \\
omega & 0.701 & 0.752 & 0.806 & 0.778 & 0.811 \\
lambda 6 & 0.709 & 0.760 & 0.813 & 0.788 & 0.817 \\
\hline SDMS & Wave 1 & Wave 2 & Wave 3 & Wave 4 & Wave 5 \\
\hline alpha & 0.857 & 0.891 & 0.933 & 0.925 & 0.944 \\
omega & 0.930 & 0.964 & 0.970 & 0.971 & 0.981 \\
lambda 6 & 0.893 & 0.928 & 0.948 & 0.942 & 0.963 \\
\hline
\end{tabular}

the consent letter. They were informed that they would be asked to attend five assessments over a 3-years period. Data were collected periodically at the end of each academic semester, but before the final exams period. Participants were tested either individually or in groups of up to 30 . Students were informed about the scientific goal of the study (i.e., to examine the relation between the way they think about their decisions and the amount of feedback about themselves they prefer to receive). All individuals consented to share their personal information with the researchers and provided their first names, surnames, student identification numbers, e-mail addresses, and agreed to attend for follow-up. A trained research assistant or an investigator administered the sessions. During each evaluation participants were asked to follow the instructions on their questionnaire booklets. After filling in demographic data, participants were given two questionnaires, the MCSQ-21 and the SDMS. At all five waves of the study, the two questionnaires were presented in random order. The effect of tests' randomization was insignificant: $F<1$. We used paper-and-pencil versions of the scales to ensure the participants' compliance with the study procedure. Hard copies were stored at the University of Gdansk, ensuring the security of personally identifiable information. As each participant turned in their completed questionnaires, they were thanked and asked to schedule the next assessment session. Participants who completed their last assessment, either because their further participation was not possible or because of the end of the study period (i.e., the fifth wave), were fully debriefed. No compensation was offered for participation.

In summary, the cohort was followed for 2.5 years and five measurements were taken. Both metacognitive self and the willingness to search for self-diagnostic information were assessed at each time point, allowing for both the concurrent associations as well as the prospective associations to be examined.

\section{RESULTS}

To assess Hypothesis 1 that changes in the drive to seek selfdiagnostic information (SDMS) would be due to the level of metacognitive self (MCS), data were first fit using a linear growth model with fixed effects of MCS on the intercept (baseline assessment) and linear (score of the SDMS) terms and random effects of participants on the intercept and slope to model 


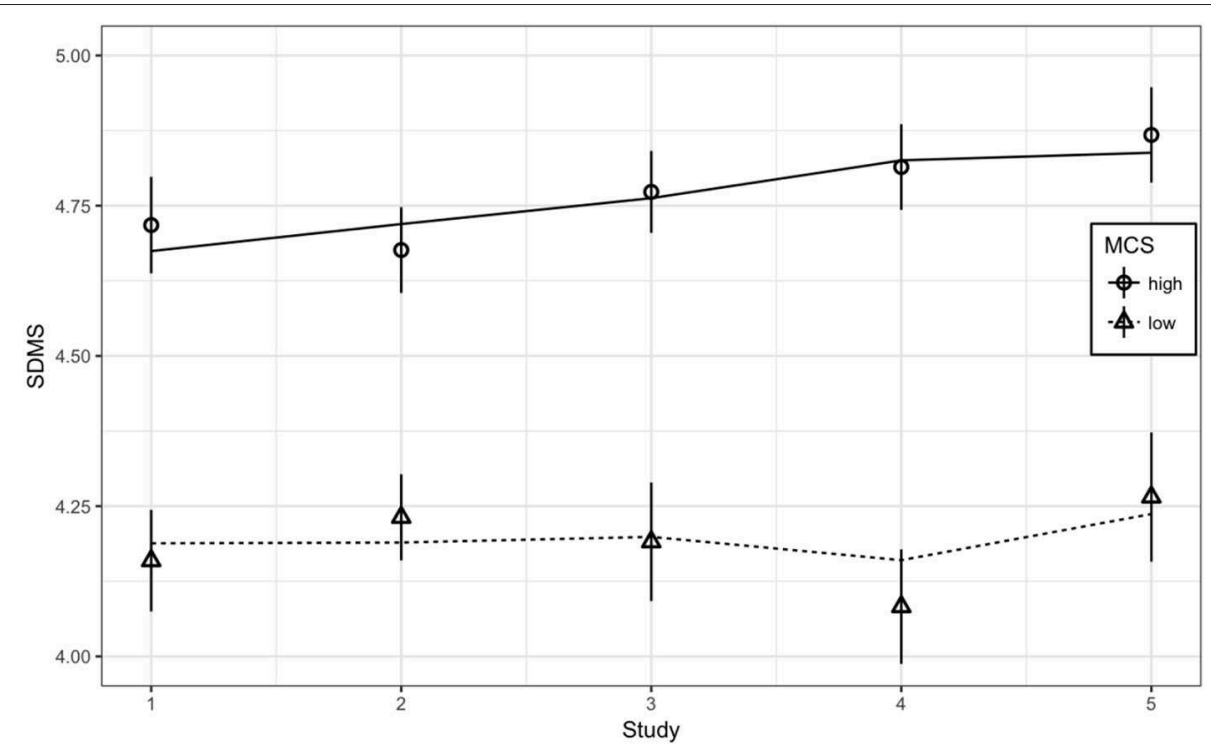

FIGURE 1 | Estimated growth curves of SDMS for individuals with low and high initial scores of MCS.

individual differences in the initial scores and rate of growth (Bates et al., 2015). The fixed effect of MCS on model fit was evaluated using model comparisons. Improvements in model fit were evaluated using -2 times the change in log-likelihood, which is distributed as $\chi^{2}$ with degrees of freedom equal to the number of parameters added (which was 1 for all comparisons). The analyses were carried out in $\mathrm{R}$ version 3.4.3 using the lme4 package (version 1.1-15; R Core Team, 2017).

The data and the model fit are shown in Figure 1. The results indicate that there was a significant MCS effect on the intercept, $\chi^{2}(1)=80.4, p<0.001$, and no effect on the slope, $\chi^{2}(1)=$ $1.46, p=0.227$. Thus, the individuals who exhibited high level of MCS had stronger drive to seek self-diagnostic information than participants showing low level of MCS. The initial level of SDMS was $1.61 \mathrm{pts}(S E=0.48)$. The growth of SDMS was assessed on 0.19 pts $(S E=0.15)$ at each wave of the study, and the influence of MCS was assessed on 0.65 pts $(S E=0.11)$.

However, as can be seen on Figure 1, the two lines, representing relation between MCS and SDMS, are essentially parallel over the five waves of the study. This parallelism of the curves is evident form insignificant differences in the slopes. Thus, the predictor (i.e., MCS) was treated as continuous variable in the analyses. The discrete grouping was used solely to provide a clearer visual representation of the effects.

Notwithstanding the above, Figure 1 depicts the growth of the relation between MCS as the prospective predictor and the SDMS total score as the dependent measure. In Figure 2, we present the correlations between the MCS level obtained at each measurement point and the SDMS level as measured during the subsequent assessment session. The significant associations $(r=0.13-0.30)$ support our Hypothesis 1 , and indicate that MCS, measured $\sim 6$ months earlier, significantly predicted the drive to seek self-diagnostic information. Table 2 shows intercorrelations between MCS and SDMS at all waves of the
TABLE 2 | Intercorrelations between SDMS and MCS across all studies.

\begin{tabular}{lccccc}
\hline & SDMS 1 & SDMS 2 & SDMS 3 & SDMS 4 & SDMS 5 \\
\hline MCS 1 & 0.282 & 0.128 & 0.142 & 0.211 & 0.106 \\
MCS 2 & 0.203 & 0.283 & 0.180 & 0.231 & 0.191 \\
MCS 3 & - & 0.271 & 0.254 & 0.301 & 0.247 \\
MCS 4 & - & - & 0.296 & 0.359 & 0.280 \\
MCS 5 & - & - & - & 0.284 & 0.272 \\
\hline
\end{tabular}

All correlations are statistically significant at $p<0.001$.

TABLE 3 | MCS as a predictor for the SDMS subscales: ORI (information about own results), SII (self-improvement information), and $\mathrm{Cl}$ (comparison information concerning own and others' results) at all five waves of the study.

\begin{tabular}{lccccc}
\hline $\begin{array}{l}\text { Subscales } \\
\text { of the SDMS }\end{array}$ & Wave 1 & Wave 2 & Wave 3 & Wave 4 & Wave 5 \\
\hline ORI & $0.26^{\star \star}$ & $0.26^{\star \star}$ & $0.24^{\star \star}$ & $0.40^{\star \star}$ & $0.30^{\star \star}$ \\
SII & $0.28^{\star \star}$ & $0.22^{\star \star}$ & $0.25^{\star \star}$ & $0.34^{\star \star}$ & $0.32^{\star \star}$ \\
Cl & $0.16^{\star}$ & $0.17^{\star}$ & $0.21^{\star}$ & $0.29^{\star \star}$ & $0.20^{\star}$ \\
\hline
\end{tabular}

${ }^{*} p \leq 0.05 ;{ }^{* *} p<0.01$.

study. As indicated in Table 2, and in line with our Hypotheses 1 and 2, MCS showed significant prospective and concurrent relations with SDMS.

According to Hypothesis 3, we expected that the associations of MCS with seeking own results information (ORI) and selfimprovement information (SII) would be stronger than with seeking information about the self compared to others (CI), as the latter is likely to involve self-enhancement. The results, displayed in Table 3, do not confirm our hypothesis. Across all assessments, the correlations of MCS with the SDMS subscales were all positive and ranged from $r=0.20$ to $r=0.40$ for ORI and SII and from 


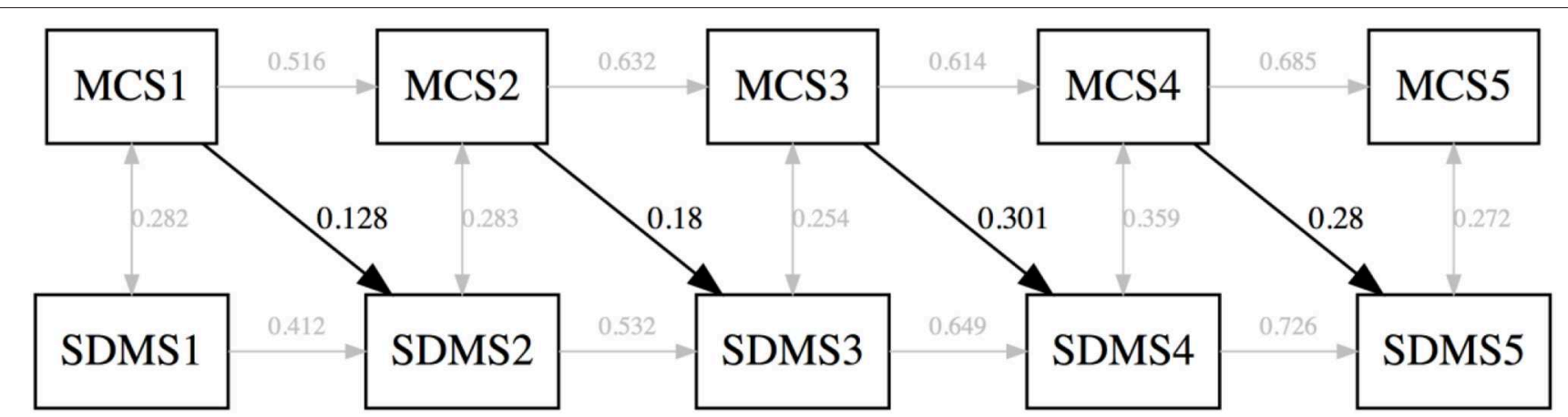

FIGURE 2 | Pearson's correlations (black one headed arrows and gray double headed arrows) and reliability coefficients (test-retest correlation; gray one headed arrows).

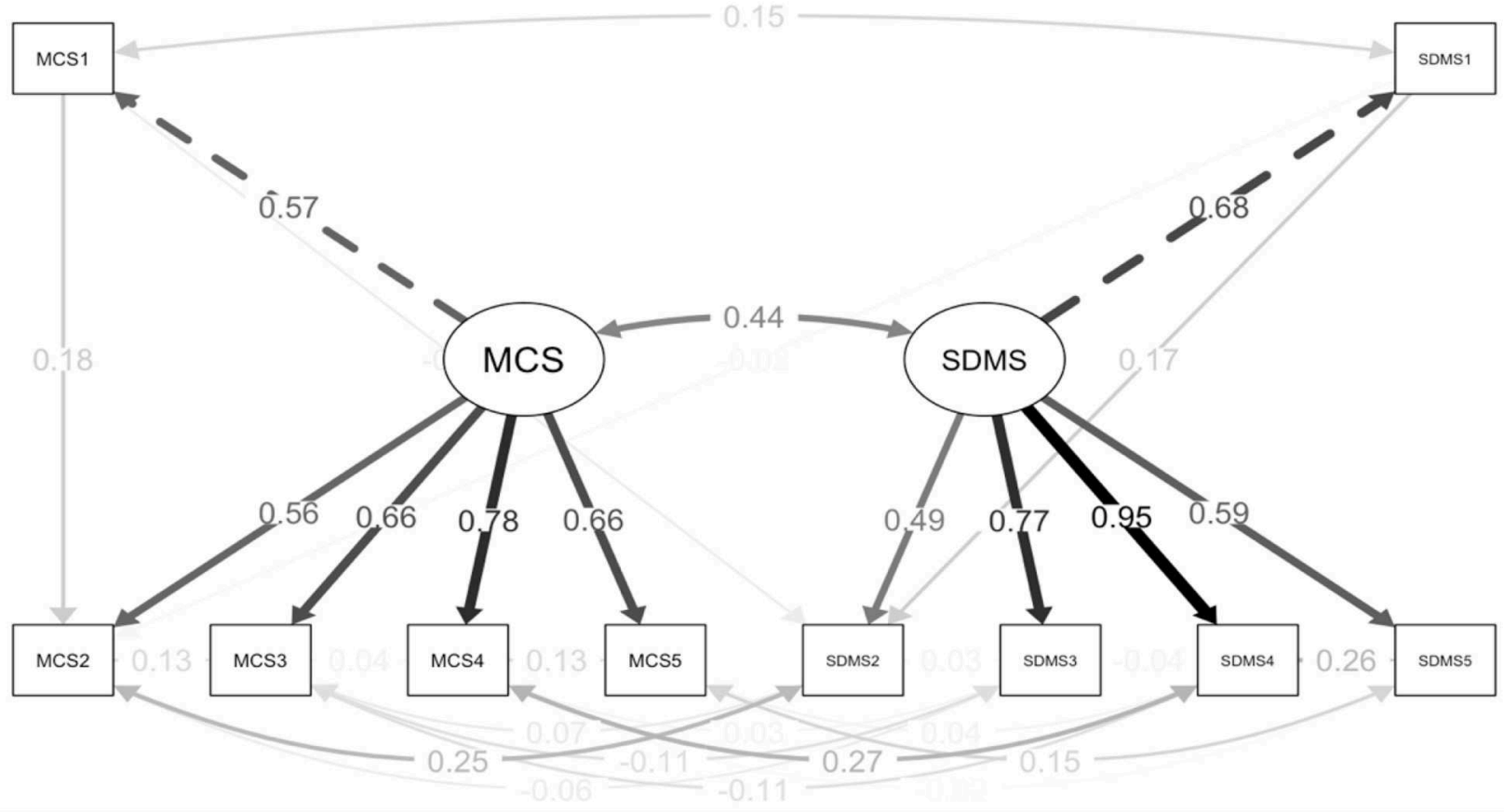

FIGURE 3 | EFA model with standardized estimates. Magnitudes of the estimates are reflected by the intensity of the black color.

$r=0.16$ to $r=0.29$ for CI. Although MSC correlated slightly higher with ORI and SII than with CI, it should be noted that all correlations were significant and did not differ significantly from each other. Thus, the stronger the self-awareness of biases, the more participants look for self-diagnostic information, regardless of the type of feedback.

To further test the influence of MCS on SDMS we modeled latent variables for MCS and SDMS, with scores at each of the five waves as indicators. These latent variables reflected stable variances of MCS and SDMS. We separately modeled wave-specific scores on MCS and SDMS to capture withinperson variability on these variables. The model specified autoregressions involving within-person deviations from the mean in MCS and SDMS over time as well as predictions from within-person deviations from mean levels of MCS to within-person deviations from the mean of SDMS measured the following wave and from SDMS to MCS measured the following wave. The variables within the measurement wave were allowed to covary. The resulting model, depicted in Figure 3, provided a good fit to the data: $\chi^{2}(13)=7.745, p=0.860, \mathrm{CFI}=1.00$, AGFI $=0.977$, RMSEA $=0$, CI95 [0-0.032]. As indicated in Figure 3, the correlation between the latent variables, reflecting stable variances of MCS and SDMS, was $r=0.44$ and showed that, overall, participants who were high in MCS were more eager to seek self-diagnostic information than those who were low in MCS. However, beyond the stability of MCS and the stability of SDMS, the prospective effect of MCS on SDMS was small. 


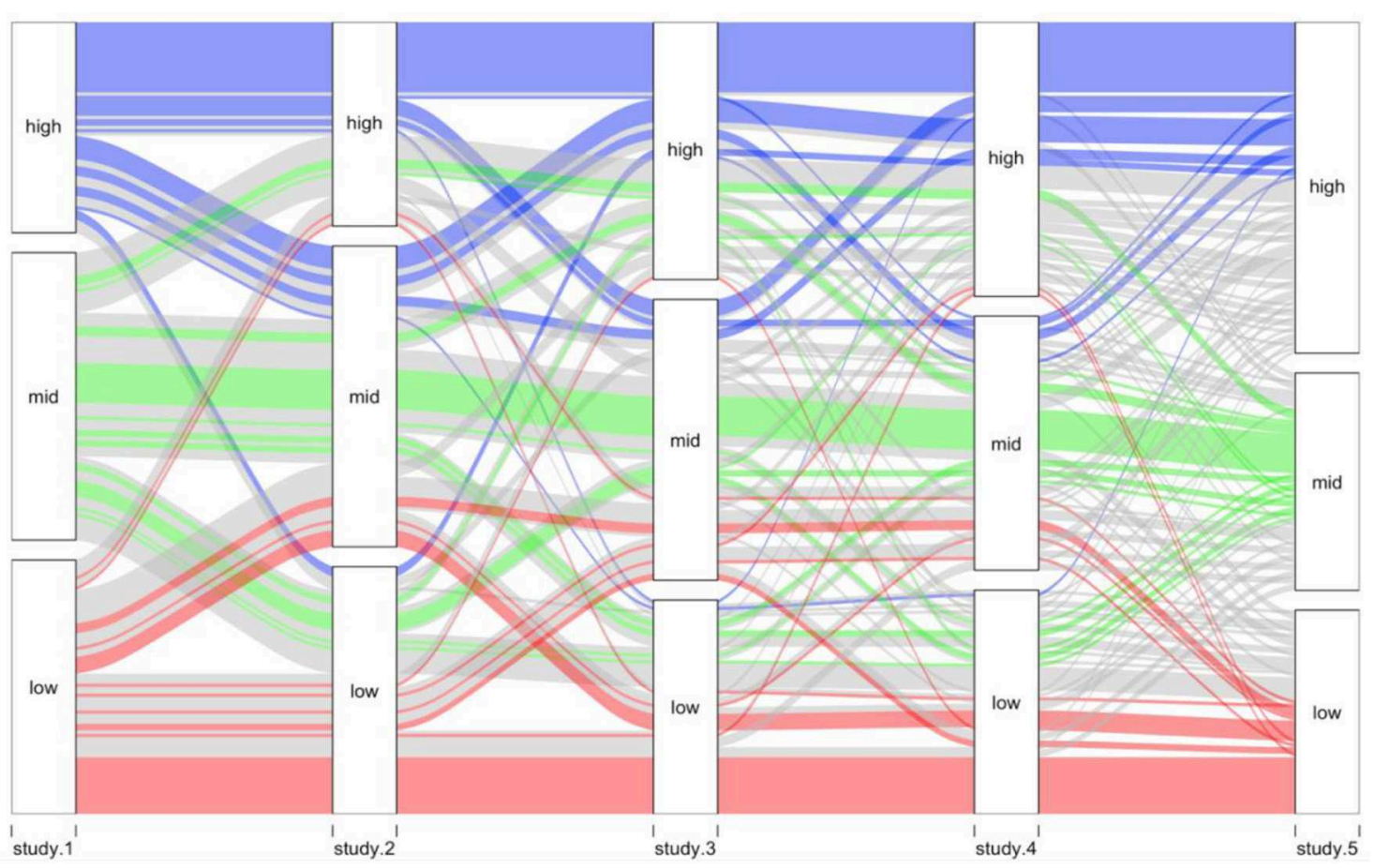

FIGURE 4 | Plot for each participant's level of SDMS over all five measurements. Each line represents each individual's SDMS score; the lines are color-coded with respect to the initial and final level of SDMS: participants low in SDMS $(<4)$ are marked in red, those moderate in SDMS are marked in green $(4<x<5)$, and those high in SDMS (>5) are marked in blue.

From the results presented in Figures 2, 3, it can be concluded that MCS is not a strong predictor of SDMS. A possible explanation for this finding is illustrated in Figure 4, which shows the fluctuation of each participant's SDMS across the five measurement points. As can be seen, changes in the drive for self-diagnostic information were not linear. It appears that motivation to search for self-diagnostic is a complex phenomenon, and is influenced by other psychological variables in addition to MCS.

\section{DISCUSSION}

This study examined the relation between metacognitive self and the desire for self-diagnostic information both concurrently and prospectively. More than 400 emerging adults participated in the 2.5-years project, with five assessment waves, each 6 months apart. The obtained results show that MCS is related significantly and positively to SDMS, both concurrently and prospectively, thus offering support for Hypotheses 1 and 2. The associations of MCS with each of the SDMS subscales did not differ significantly, thus failing to support Hypotheses 3.

Consistent with Hypothesis 1, in the prospective analysis, stronger MCS significantly predicted subsequently greater desire for self-diagnostic information. Moreover, this prospective association of strong MCS with increased SDMS was evident across each interval that the association could be tested. However, as determined by the linear growth model analysis, MCS did not explain interindividual differences in intraindividual change in SDMS. Individuals high in MCS did not differ from those low in MCS in the rate of growth of SDMS. This finding suggests that the effect of MCS on the level of SDMS remains rather constant over time.

In the concurrent analysis, in line with Hypothesis 2, stronger MCS significantly predicted greater SDMS. This positive effect was reproduced at each assessment point. Given the content of the SDMS subscales, we expected that MCS would correlate more strongly with seeking own results information (ORI) and selfimprovement information (SII) than with seeking comparison information (CI; Hypothesis 3). Such a pattern of results was expected based on the evidence that social comparisons can also serve self-enhancement functions (e.g., Wills, 1981). The observed correlations indicated, however, that MCS related positively to all of the SDMS subscales to about the same degree. Thus, the data failed to show the expected preference of individuals high in MCS for seeking information on selfimprovement and one's own performance. The above results seem compatible with the assertion that there is a strong common factor underlying the desire for various self-diagnostic information (Brycz et al., 2018).

Our findings are consistent with those of previous research on linkage between metacognitive self and the desire for selfdiagnostic information (Brycz et al., submitted; Brycz et al., 2018). In the past experimental study MSC was found to be effective in explaining interindividual differences in seeking self-diagnostic information when confronted with a negative 
feedback. The current study extends these findings and provides evidence that the two constructs are positively related also at the trait level.

The present study represents the first to examine the longitudinal predictive power of MCS. MCS was shown to be positively predictive of seeking self-diagnostic information both concurrently and across time. Our findings support the reasoning outlined in the introduction and above cited reports of greater interest in feedback among individuals with high MCS. They also align with research on the mechanisms underlying monitoring of own knowledge as well as with research on strategies for learning and remembering (Koriat et al., 2014). For example, on the basis of taking into account self-diagnostic information, judgments of learning are assumed to rely on subjective effort invested in searching diagnostic information on the process in question (Koriat et al., 2014). The motivation to maintain the metacognitive level of thinking is thus intrinsic. Koriat et al. (2009) demonstrated a developmental increase in data-driven regulation, resulting from seeking and considering diagnostic information about the self.

The current results also contribute to the growing body of research on regulatory functions of metacognitive self. Prior studies have shown that individuals high in MCS, compared to those with low MCS, are more persistent in the face of challenges and recognize more uncontrollable events in their environment and themselves. The present results may further suggest that the associations of MCS with persistence and recognition of properties of events may in part be due to the increased need for self-diagnostic information associated with stronger MCS. As Bandura (1991) mentioned, conscious and purposeful selfobservation may provide self-diagnostic feedback, which has an important self-motivating function and can modify one's course of action.

Learning crucial information about the self at the metacognitive level and acquiring essential knowledge of how individuals understand the world around them and themselves is of considerable practical and theoretical interest for learners, educators, and researchers (Holland et al., 1989). Of particular importance in this context is the finding of Yang et al. (2017) that testing of previously learnt information enhances learning and retention of new information (i.e., the forward testing effect). This finding could suggest that the drive to search for self-diagnostic information may enhance knowledge of one's own biases and heuristics as well as strengthen self-knowledge in general.

\section{Limitations and Future Directions}

Certain limitations of this study need to be highlighted. First, it is important to note that all data were self-reported,

\section{REFERENCES}

Arnett, J. J. (2000). Emerging adulthood: a theory of development from the late teens through the twenties. Am. Psychol. 55, 469-480. doi: 10.1037/0003-066X.55.5.469

Bandura, A. (1991). "Social cognitive theory of moral thought and action," in Handbook of Moral Behavior and Development: Vol. 1. Theory, eds W. M. Kurtines, and J. L. Gewirtz (Hillsdale, NJ: Lawrence Erlbaum), 45-103. which introduces the potential of confounding construct with method variance. Our study's longitudinal design allowed for an examination of the relationship between self-reported MCS measured at one point in time with self-reported SDMS measured at the subsequent time period and thereby reduced the plausibility of common-method-variance explanations for the results. Nevertheless, because cross-sectional data were also collected, we cannot entirely rule out common method variance as a source of bias in the results. Furthermore, the present study did not examine any of the exogenous variables that might determine individuals' tendency to look for self-diagnostic information. Most likely, there are many other self-related, affective, and motivational factors that play a vital role in the self-evaluation process (e.g., self-esteem). Finally, despite the large longitudinal response rate, we cannot exclude the possibility that the loss of participants at followup assessments limited the representativeness of the sample and the generalizability of our findings. Further studies should include testing of more complex models using additional measures of constructs relevant to processing information about the self and include both self-ratings and non-selfreport assessments.

\section{DATA AVAILABILITY STATEMENT}

All datasets generated for this study are included in the manuscript/supplementary files.

\section{ETHICS STATEMENT}

The study was reviewed and approved by the Polish Ethical Committee (decision no 17a/2013). Written informed consent was obtained from all participants in accordance with the Declaration of Helsinki.

\section{AUTHOR CONTRIBUTIONS}

HB contributed the conception and design of the study. AF organized the database. PK performed the statistical analysis. $\mathrm{HB}, \mathrm{PK}$, and $\mathrm{AP}$ wrote the sections of the manuscript. $\mathrm{HB}$ and $\mathrm{AP}$ contributed to the manuscript revision. All authors read and approved the submitted version.

\section{FUNDING}

This study was funded by the National Science Centre (Poland; grant number 2013/11/B/HS6/01463).

Bassok, M., and Trope, Y. (1984). People's strategies for testing hypothesis about another's personality: confirmatory or diagnostic? Soc. Cogn. 2, 199-216. doi: 10.1521/soco.1984.2.3.199

Bates, D., Mächler, M., Bolker, B., and Walker, S. (2015). Fitting linear mixedeffects models using lme4. J. Stat. Softw. 67, 1-48. doi: 10.18637/jss.v067.i01

Baumeister, R. F., and Vohs, K. D. (eds.). (2004). Handbook of SelfRegulation: Research, Theory, and Applications. New York, NY: Guilford Press. 
Brinol, P., and DeMarree, K. G. (eds.). (2012). Social Metacognition. New York, NY: Psychology Press.

Brycz, H., Karasiewicz, K., and Klimaszewska, J. (2014). Interdependence of metacognitive self and selected aspects of cognitive functioning. Pol. Psychol. Forum 19, 401-408. doi: 10.14656/PFP20140308

Brycz, H., Konarski, R., Kleka, P., and Wright, R. (2019). The metacognitive self: the role of motivation and an updated measurement tool. Econ. Sociol. 12, 208-232. doi: 10.14254/2071-789X.2019/12-1/12

Brycz, H., Wyszomirska-Góra, M., Konarski, R., and Wojciszke, B. (2018). The metacognitive self fosters the drive for self-knowledge: the role of the metacognitive self in the motivation to search for diagnostic information about the self. Pol. Psychol. Bull. 49, 66-76. doi: 10.24425/119473

Buchler, R., Griffin, D., and Ross, M. (1994). Exploring the "planning fallacy": why people underestimate their task completion times. J. Pers. Soc. Psychol. 67, 366-381. doi: 10.1037/0022-3514.67.3.366

Flavell, J. H. (1979). Metacognition and cognitive monitoring: a new area of cognitive-developmental inquiry. Am. Psychol. 34, 906-911. doi: 10.1037/0003-066X.34.10.906

Higgins, E. T., and Kruglanski, A. W. (eds.). (2000). Motivational Science: Social and Personality Perspectives. New York, NY: Psychology Press.

Holland, J. H., Holyoak, K. J., Nisbett, R. E., and Thagard, P. R. (1989). Induction: Process of Inference, Learning, and Discovery. Cambridge: MIT Press. doi: $10.7551 /$ mitpress/3729.001.0001

Kahneman, D., and Tversky, A. (1973). On the psychology of prediction. Psychol. Rev. 80, 273-251. doi: 10.1037/h0034747

Koriat, A. (2007). "Metacognition and consciousness," in The Cambridge Handbook of Consciousness, eds P. Zelazo, M. Moscovitch, and E. Thompson (New York, NY: Cambridge University Press), 289-325. doi: $10.1017 /$ CBO9780511816789.012

Koriat, A., Ackerman, R., Adiv, S., Lockl, K., and Schneider, W. (2014). The effects of goal-driven and data-driven regulation on metacognitive monitoring during learning: a developmental perspective. J. Exp. Psychol. Gen. 143, 386-403. doi: $10.1037 / \mathrm{a} 0031768$

Koriat, A., Ackerman, R., Lockl, K., and Schneider, W. (2009). The memorizing effect heuristic in judgments of learning: a developmental perspective. J. Exp. Child Psychol. 102, 265-279. doi: 10.1016/j.jecp.2008.10.005

Koriat, A., Lichtenstein, S., and Fischhoff, B. (1980). Reasons for overconfidence. J. Exp. Psychol. Hum. Learn. Memory 6, 107-118. doi: 10.1037//0278-7393. 6.2.107

Kross, E., and Ayduk, O. (2017). "Self-distancing: theory, research, and current directions," in Advances in Experimental Social Psychology: Vol. 55. Advances in Experimental Social Psychology, ed J. M. Olson (San Diego, CA: Elsevier Academic Press), 81-136. doi: 10.1016/bs.aesp.2016.10.002

Kruglanski, A. W. (1989). Lay Epistemics and Human Knowledge: Cognitive and Motivational Bases. New York, NY: Plenum. doi: 10.1007/978-1-4899-0924-4

Landau, M. J., Greenberg, J., and Kosloff, S. (2010). "Coping with life's one certainty: a terror management perspective on the existentially uncertain self," in Handbook of the Uncertain Self, eds R. M. Arkin, K. C. Oleson, and P. J. Carroll (New York, NY: Psychology Press), 195-215.

Larrik, R. P. (2004). "Debiasing," in Blackwell Handbook of Judgment and Decision Making, eds D. J. Koehler, and N. Harvey (Oxford: Blackwell Publishing), 316-337. doi: 10.1002/9780470752937.ch16

Ling, I.-L., Chuang, S.-C., and Hsiao, C.-H. (2012). The effects of selfdiagnostic information on risk perception of internet addiction disorder: selfpositivity bias and online social support. J. Appl. Soc. Psychol. 42, 2111-2136. doi: 10.1111/j.1559-1816.2012.00933.x

Monteil, J. M., and Michinov, N. (1996). Study of some determinants of social comparison strategies using a new methodological tool. Towards a dynamic approach. Eur. J. Soc. Psychol. 26, 981-999. doi: 10.1002/(SICI)1099-0992(199611)26:6<981::AID-EJSP801> 3.0.CO;2-2

Morrison, E. W., and Cummings, L. L. (1992). The impact of feedback diagnosticity and performance expectations on feedback seeking behavior. Hum. Perform. 5, 251-264. doi: 10.1207/s15327043hup0504_1

Nelson, T., and Narens, L. (1990). "Metamemory: a theoretical framework and new findings," in The Psychology of Learning and Motivation: Advances in Research and Theory, Vol. 26, ed G. H. Bower (San Diego, CA: Academic Press), 125-173. doi: 10.1016/S0079-7421(08)60053-5

Nisbett, R. E., and Ross, L. (1980). Human Inference: Strategies and Shortcomings of Social Judgment. Englewood Cliffs, NJ: Prentice-Hall.

R Core Team (2017). R: A Language and Environment for Statistical Computing. Retrieved from: https://www.R-project.org/

Sachs, J. (2001). Aristotle's on the Soul and Memory and Recollections. Santa Fe, NM: Green Lion Press.

Scholer, A. A., and Miele, D. B. (2016). The role of metamotivation in creating taskmotivation fit. Motiv. Sci. 2, 171-196. doi: 10.1037/mot0000043

Schraw, G., and Dennison, R. S. (1994). Assessing metacognitive awareness. Contemp. Educ. Psychol. 19, 460-475. doi: 10.1006/ceps.1994.1033

Schwarz, N. (2015). "Metacognition." in APA Handbooks of Personality and Social Psychology: Attitudes and Social Cognition, eds M. Mikulincer, P. R. Shaver, E. Borgida, and J. A. Bargh (Washington, DC: American Psychological Association), 203-229.

Sedikides, C., and Skowronski, J. J. (2000). "On the evolutionary functions of the symbolic self: the emergence of self-evaluation motives," in Psychological Perspectives on Self and Identity, eds A. Tesser, R. Felson, and J. M. Suls (Washington, DC: American Psychological Association), 91-117. doi: $10.1037 / 10357-004$

Sedikides, C., and Skowronski, J. J. (2009). Social cognition and self-cognition: two sides of the same evolutionary coin? Eur. J. Soc. Psychol. 39, 1245-1249. doi: $10.1002 /$ ejsp. 690

Sedikides, C., and Strube, M. J. (1997). "Self-evaluation: to thine own self be good, to thine own self be sure, to thine own self be true, and to thine own self be better," in Advances in Experimental Social Psychology, Vol. 29, ed M. P. Zanna (San Diego, CA: Academic Press), 209-269. doi: 10.1016/S0065-2601(08)60018-0

See, Y. H. M., Petty, R. E., and Fabrigar, L. R. (2008). Affective and cognitive metabases of attitudes: unique effects on information interest and persuasion. J. Pers. Soc. Psychol. 94, 938-955. doi: 10.1037/0022-3514.94.6.938

Simmons, S. J., Bickart, B. A., and Lynch, L. G. (1993). Capturing and creating public opinion in survey research. J. Consum. Res. 20, 316-329. doi: $10.1086 / 209352$

Taylor, S. E., Neter, E., and Wayment, H. A. (1995). Self-evaluation processes. Pers. Soc. Psychol. Bull. 21, 1278-1287. doi: 10.1177/014616 72952112005

Trope, Y., and Neter, E. (1994). Reconciling competing motives in self-evaluation: the role of self-control in feedback seeking. J. Pers. Soc. Psychol. 66, 646-657. doi: 10.1037/0022-3514.66.4.646

Tversky, A. (1977). Features of similarity. Psychol. Rev. 84, 327-352. doi: $10.1037 / 0033-295 X .84 .4 .327$

Weiner, B. (1972). Theories of Motivation: From Mechanism to Cognition. Oxford: Markham.

Weiner, B. (2014). An anecdotal history of motivation. Rev. Psychol. 57, 299-320.

Whittlesea, B. W. A. (1993). Illusions of familiarity. J. Exp. Psychol. Learn. Memory Cogn. 19, 1235-1253. doi: 10.1037/0278-7393.19.6.1235

Wills, T. A. (1981). Downward comparison principles in social psychology. Psychol. Bull. 90, 245-271. doi: 10.1037/0033-2909.90.2.245

Yang, C., Potts, R., and Schanks, D. R. (2017). Metacognitive unawareness of the effortful generation benefit and its effect on self-regulated learning. J. Exp. Psychol. Learn. Memory Cogn. 43, 1073-1092. doi: 10.1037/ xlm0000363

Conflict of Interest: The authors declare that the research was conducted in the absence of any commercial or financial relationships that could be construed as a potential conflict of interest.

Copyright (๑) 2019 Brycz, Kleka, Fanslau and Pilarska. This is an open-access article distributed under the terms of the Creative Commons Attribution License (CC BY). The use, distribution or reproduction in other forums is permitted, provided the original author(s) and the copyright owner(s) are credited and that the original publication in this journal is cited, in accordance with accepted academic practice. No use, distribution or reproduction is permitted which does not comply with these terms. 